IOSR Journal of Pharmacy

e-ISSN: 2250-3013, p-ISSN: 2319-4219, www.iosrphr.org

Volume 2 Issue 6 ||| Nov-Dec. 2012 || | PP.47-51

\title{
A retrospective and prospective study of spinal injuries in children and adolescent- incidence etiology and early outcome
}

\author{
Daya Krishna ${ }^{1}$, Vikas sikarwar ${ }^{2}$, R.S Bisht ${ }^{2}$, Shubash Chand. ${ }^{1}$ \\ ${ }^{1}$ Department of Orthopedics; Veer Chandra Singh Garhwali Govt. Medical Science and \\ Research Institute, Srinagar, UK, India. \\ ${ }^{2}$ Department of E.N.T and Head \& Neck Surgery; Veer Chandra Singh Garhwali Govt. Medical \\ Science and Research Institute, Srinagar, UK, India.
}

\begin{abstract}
Background- Traumatic spinal injuries in children consists up to $10 \%$ of all reported spinal injuries. The true incidence may be underestimated because of mortality at the site or during transport. The level of injury and incidence of neurological compromise varies with the age of child. The infants, toddlers, school age children and adolescents have distinctive anatomic and biomechanical spinal features and behavioral patterns that distinguish them not only from adults but also from each other in this study we analyses all parameter of differences.

Material And Method-This is a two years retrospective and one year prospective study of spinal injuries in children and adolescent age up to 18 years admitted in spinal injury unit of orthopaedics surgery King George's Medical University Lucknow to evaluate incidence, etiology and early outcome. Following variables were studied in these retrospective and prospective-(1) age and sex (2) injury mechanism (3) associated injuries (4) injury level (neurological and radiological) (5) management and early outcome (6) deformity evaluation

Result- Total number of patients was 82 of which 68 were retrospective and 26 were prospective, incidence was 13.21/ year/1000, male female ratio 3.1:1, no infant, toddlers -6(7.31\%), school going 17(21.73\%), adolescent 59(71.95\%). Most common mechanism of injury was fall from height followed by road traffic accident, most common neurological and radiological level $\mathrm{C5}-\mathrm{C} 7$, conservative management done in 78 and operative in 4 patients of which 35 improve, 23 not improve, 16 drop out and 4 expired. In prospective study FIM score increase in all patient except one and Barthal index not improve in two patients. Deformity present in 21 prospective and 4 retrospective patients kyphotic deformity of $>15$ degree found in 13 patients a mild progression of 4.23 degree was noted in follow up.

Conclusions- In children and adolescent the incidence of spinal injury, mechanism of injury, neurological and vertebral level are different at different age groups and outcome is depends on extent of injury complete $(A)$, incomplete $(B, C, D)$ of ASIA impairment scale and motor and sensory score after spinal shock is over. The development of deformity is determined by age, extent of injury, vertebral level at the time of injury.
\end{abstract}

Keywords—Demography, functional independence measure (FIM), Cobb's angle, and Barthal index.

\section{INTRODUCTION}

Traumatic spinal injuries in children consist up to $10 \%$ of all reported spinal injuries. The true incidence may be underestimated because of mortality at site or during transport. Younger children present an additional challenge to communicate crucial symptoms and lack of cooperation. Anatomic differences between the pediatric and adult spine are prominent until approximately eight years of age and persist to a lesser degree approximately twelve years of age ${ }^{1,2,3,4,5}$. As a result details of presentation of spinal injury in adult are not necessarily applicable to the children. The injury pattern varies significantly according to the age of children at the time of injury ${ }^{6}$.

There is progressive change in anatomic and physiologic structure of the childhood vertebral column and spinal cord, which necessitate unique and specific evaluation of each age group. Children have many physiologic characteristic that predisposes them to spinal injury. Among these are a disproportionately large head, underdeveloped neck musculature, relatively vertical facet joints, ligamentous laxity and shallow angulations of facet joints and incomplete ossification of vertebral bodies ${ }^{7,8}$. 
The level of injury and incidence of neurological compromise varies with the age of child. Infant, toddlers, school age children and adolescents have distinctive anatomic and biomechanical spinal features and behavioral pattern that distinguish them not only from adults but also from each other ${ }^{9,10}$.

Mechanism of injury can be stratified further by age. Fall is the most common cause of traumatic spinal injuries in toddlers and school age group because of proportionally larger heads, high center of gravity, and decrease coordination than older children predispose them to falls. Adolescent have same physical characteristics as adults but there different behavioral characteristics reflects in mechanism of injury which are sports, road traffic accidents, and youth violence ${ }^{11,12}$.

Some literature suggested that young children have a predilection for higher cervical spine injuries in the form of cervical spine dislocation and SCIWORA, whereas older children are more likely to sustain cervical spine fracture ${ }^{6}$ which explained by biomechanical and anatomic difference that exists in developing pediatric cervical spine. SCIWORA was defined as spinal cord injury without evidence of bone injury including CT, MRI as diagnostic tools ${ }^{13,14}$. According to some literature it is very rare in children and some says it is more common in younger children and children suffering from child abuse. ${ }^{2,3,5,7,15}$

The completeness and incompleteness of neurologic injury between children greater and less than 8 years of age is similar, suggesting that anatomic differences not play a role in symptomatic spinal injury ${ }^{16}$. In children, a traumatic spinal injury may develop a deformity that is mainly scoliotic, kyphotic or lordotic in more than $90 \%$ of $\operatorname{cases}^{17}$. According to the literature the level and extent of spinal injury and the age at the time of injury are determinants of the development of deformity ${ }^{18}$.

Conservative treatment was successful in all stable fractures, whereas it failed in unstable injuries and leads to severe deformity. The functional gain measured by FIM (functional independence measure) and Barthal index was not significantly related to age, sex and duration of rehabilitation, pathogenesis, or completeness or neurologic level of injury. However there is a trend for higher functional gain for patient with incomplete spinal cord injury and traumatic spinal cord injury ${ }^{19}$. After severe traumatic spinal cord injury the incidence of recovery of neurologic function is greater in children than adult and this occurs over a prolonged post injury period. $^{20}$

\section{MATERIAL AND METHOD}

This study is meant to the incidence, etiology and early outcome of spinal injuries in children and adolescent presenting at spinal injury unit of Department of Orthopaedics King George s Medical University, Lucknow.

Criteria of inclusion and exclusion - All patients of traumatic spinal injuries (up to 18 years of age) admitted in spinal injury unit between 16 August 2005 to July 2006 for prospective study and between January 2004 to December 2005 for retrospective study from records of spinal injury unit and follow up in OPD were included in study. Patient having severe head injury, chest injury, abdominal injury and hospital stay less than 48 hours were excluded from the study.

Demographics - All patients were divided into male and female according to sex and into four groups, infant (0-1 year), toddler (1-5 years), school going (5-12 years), adolescent (12-18years) according to age.

Injury mechanism - It was divided into 7 groups as follows- fall from height (FFH), road traffic accident (RTA), fall of weight (FOW), hit by animal, fire arm injury, sports/diving and other in which other than these mechanism were included.

Associated injury - After using inclusion and exclusion criteria were studied in following groupsmaxillofacial, craniocerebral, genitourinary, respiratory, GIT and not any(without any associated injury.

Investigation - AP and lateral X-ray view spine was done in all patients at the time of admission , discharge and follow up special view like open mouth, swimmer's view or oblique view for facet joint was taken when indicated CT, MRI were done depending on affordability of patient.

Neurological evaluation - In prospective cases done as per ASIA impairment scale, ASIA grading system and KGMU grading system, in retrospective cases as per KGMU grading system in which we record muscle power at shoulder, elbow, wrist, grip of hand in upper limb at hip, knee, ankle, foot and great toe in lower limb and all deep and superficial reflexes, bladder bowel involvement and level of sensory deficit were noted at the time of admission, discharge and follow up.

Deformity evaluation - It is done by cobbs angle as seen in AP and lateral view of spine at the time of admission, discharge and follow up.

Functional evaluation - In prospective cases done by functional independence measure and Barthal index and improvement in ASIA impairment scale and grading in retrospective cases by improvement in KGMU grading at the time of admission discharge and follow up.

Management - Patients were managed either conservatively or surgically as per stability of spine, patient affordability and choice of surgeon. Cervical spine injury patient were managed conservatively by complete bed rest, hard cervical collar, reduction maintenance by Crutchfield traction (for dislocation) and 
A retrospective and prospective study of spinal injuries in...

bladder, bowel and back care. In conservative management of thoracolumber injuries patient were managed by postural reduction and same as cervical injuries patient. In surgical management of thoracolumber injuries posterior instrumentation with or without decompression and bone grafting was done. Patient were discharge after 6 to 8 weeks and at the time of discharge orthosis like four post cervical brace, ASHE brace, Taylor brace, lumber corset was apply to patient according to level of injury. All patients were evaluated at the time of admission, at the time of discharge and in follow up.

\section{OBSERVATIONS AND DISCUSSION}

The total no of patient in our study group were 82 out of which 56 were retrospective and 26 were in prospective study group. Incidence of traumatic spinal cord injury in children and adolescents were as followsYear 2004 - total admission in SCI unit-330. Total number of children and adolescent in 2004 was -24 (7.27\%).Incidence was 72.7/year/1000.

Year 2005 -total admission in SCI unit-378.Total number of children and adolescent in 2004 was -32 (8.46\%). Incidence was 84.6/year/1000.

August 2005 to July 2006 - Total number of admission in SCI unit-278.Total number of children and adolescent in this year was - 26 (9.35\%). Incidence was 93.5/year/1000.

The mean incidence of spinal cord injury in children and adolescent in our SCI unit is 83.6/year/1000. Demographically $62(75.60 \%)$ were male and 20(24.30\%) were female, there is no patient in infant age group, toddlers $6(7.31 \%)$, school going $17(20.73 \%)$ and adolescent $59(71.95 \%)$ cases were found in this study group. No infant were found in our study group because injury among infant take place in high cervical region and craniovertibral junction and are frequently lethal at the scene. ${ }^{11}$

Table 1: Demographic of total patients of study group $(n=82)$

\begin{tabular}{cllll|}
$\begin{array}{c}\text { Age } \\
\text { Group }\end{array}$ & Male & Female Total $\%$ age \\
(Years) & & & & \\
\hline $\mathbf{0 - 1}$ & 0 & 0 & 0 & 0 \\
\hline $\mathbf{1 - 5}$ & 4 & 2 & 6 & 7.31 \\
\hline $\mathbf{5 - 1 2}$ & 14 & 3 & 17 & 20.73 \\
\hline $\mathbf{1 2 - 1 8}$ & 44 & 15 & 59 & 71.95 \\
\hline Total & 62 & 20 & 82 & 100 \\
\hline
\end{tabular}

Male female ratio $=3.1: 1$

The most common mechanism of injury in whole study group was FFH 48(58.53\%) followed by RTA $15(18.29 \%)$ other $9(10.97 \%)$ and fall of weight $8(9.75 \%)$ respectively. According to age groups RTA is common in toddlers FFH followed by RTA is common mechanism of injury in school going and adolescent in our study group. The finding of our study were inconsistent with other literature in commonest mechanism of injury as it is FFH followed RTA in our study and it is RTA followed by $\mathrm{FFH}^{10}$ in other study it may be due to differences in life style between developing and developed countries.

Table 2: Injury mechanism in total study group $(\mathbf{n = 8 2})$

\begin{tabular}{|llllllllll|}
$\begin{array}{l}\text { Age } \\
\text { Group }\end{array}$ & FFH & RTA & FOW & HBA & FAI & S\&D & Other & & \%age \\
(Years) & & & & & & & & & \\
\hline $\mathbf{0 - 1}$ & 0 & 0 & 0 & 0 & 0 & 0 & 0 & 0 & 0 \\
\hline $\mathbf{1 - 5}$ & 1 & 3 & 0 & 0 & 0 & 0 & 2 & 6 & 6.09 \\
\hline $\mathbf{5 - 1 2}$ & 10 & 5 & 1 & 0 & 0 & 0 & 1 & 17 & 23.17 \\
\hline $\mathbf{1 2 - 1 8}$ & 37 & 9 & 7 & 1 & 0 & 1 & 4 & 59 & 70.73 \\
\hline Total & 48 & 17 & 8 & 1 & 0 & 1 & 7 & 82 & \\
\hline \%age & 58.53 & 20.73 & 9.75 & 1.21 & 0 & 1.21 & 8.53 & & \\
\hline
\end{tabular}

FFH-fall from height, RTA-road traffic accident, FOW-fall of weight, HBA-hit by animal, FAI-fire arm injury, $S \& D$-sports and dive

The associated injury present in 19 patients most common of which is orthopaedic 16,2 had respiratory and 1 of GIT injury. Our findings are inconsistent with other literature it is due to difference in most common 
mechanism of injury as orthopaedic injuries are common with FFH and head injury and maxillofacial injuries are common with RTA.

The most common neurological level of injury was C5-C7 (30.48\%) followed by T1-T10 (29.26\%) and T11-L1 (21.95\%) respectively. On the basis of age groups, in toddler level of injury was equally distributed in all groups of neurological level, in school going most common level was T1-T11in 50\%,followed by C5$\mathrm{C} 7(43.75 \%)$ and rare in T11-L1 and L2-S neurological level. In adolescent most common level of injury was C5-C7 (31.51\%) followed by T1-T10 (29.82\%), T11-L1 (21\%), L2-S (12.28\%).

Table 3: Neurological Level of injury $(n=82)$

\begin{tabular}{|llllllll|}
$\begin{array}{l}\text { Age } \\
\text { Group } \\
\text { Years }\end{array}$ & $0-\mathrm{C}_{4}$ & $\mathrm{C}_{5}-\mathrm{C}_{7}$ & $\mathrm{~T}_{1}-\mathrm{T}_{10}$ & $\mathrm{~T}_{11}-\mathrm{L}_{1}$ & $\mathrm{~L}_{2}-\mathrm{S}$ & $\begin{array}{l}\text { Not } \\
\text { Tested }\end{array}$ & Total \\
\hline $\mathbf{0 - 1}$ & 0 & 0 & 0 & 0 & 0 & 0 & 0 \\
\hline $\mathbf{1 - 5}$ & 1 & 1 & 1 & 1 & 0 & 2 & 6 \\
\hline $\mathbf{5 - 1 2}$ & 1 & 7 & 8 & 0 & 0 & 1 & 17 \\
\hline $\mathbf{1 2 - 1 8}$ & 0 & 18 & 15 & 17 & 7 & 2 & 59 \\
\hline Total & 2 & 26 & 24 & 18 & 7 & 5 & \\
\hline \%age & 2.43 & 30.48 & 29.46 & 21.95 & 8.53 & 6.09 & \\
\hline
\end{tabular}

The most common level of vertebral injury wasC5-C7 (31.70\%) followed by T1-T10 (29.26\%), T11L1 (19.57\%), L2-S (9.75\%), high cervical 0-C4 (3.65\%) and SCIWORA found in (6.09\%). The neurological and vertebral level in our study is consistent with most of the literature. With increasing age vertebral injury increases in thoracic and thoracolumber region.

Table 4: Rodiological Level of injury $(n=82)$

\begin{tabular}{|llllllll|}
$\begin{array}{l}\text { Age } \\
\text { Group } \\
\text { Years) }\end{array}$ & \multicolumn{2}{c}{ Rodiological Level } & & & \\
& & $\mathrm{C}_{5^{-}}$ & $\mathrm{T}_{1}-\mathrm{T}_{10}$ & $\mathrm{~T}_{11}-\mathrm{L}_{1}$ & $\mathrm{~L}_{2}-\mathrm{S}$ & $\begin{array}{l}\text { SCIWOR } \\
\text { A }\end{array}$ & Total \\
$\mathbf{0 - 1}$ & 0 & 0 & 0 & 0 & 0 & 0 & 0 \\
\hline $\mathbf{1 - 5}$ & 1 & 1 & 1 & 0 & 1 & 2 & 6 \\
\hline $\mathbf{5 - 1 2}$ & 2 & 5 & 7 & 1 & 0 & 2 & 17 \\
\hline $\mathbf{1 2 - 1 8}$ & 0 & 20 & 16 & 15 & 7 & 1 & 59 \\
\hline Total & 3 & 26 & 24 & 16 & 8 & 5 & 82 \\
\hline \%age & 3.65 & 31.70 & 29.26 & 19.51 & 9.75 & 6.09 & \\
\hline
\end{tabular}

Management in our study group 78 patients were managed conservatively and 4 were managed by operative means (posterior instrumentation). The early outcome is as follows $35(42.68 \%)$ patient improve, 23 (32.9\%) not improve, $16(19.51 \%)$ drop out and 4(4.87\%) expires. It reflect that better improvement found in children as compare to adult. $^{20}$

Neurological evaluation was possible in 21 prospective cases in which follow up was possible it was done by using ASIA impairment scale and grading system and KGMU grading system in toddler one grade A improve to grade- D at last follow up, in school going four patient of grade- A remain grade- A and 1 case of grade- D improve to grade- E. In adolescent out of 7 grade- A at admission 6 remain grade A, one improve to grade- B, 4 cases out of 6 grade-D improve to grade-E. When sensory and motor score were evaluated we found improvement in motor score in $51.14 \%$ and sensory score in $76.19 \%$ of cases. These findings of our study are consistent with other literatures that the recoveries of neurologic function after severe traumatic spinal injuries occur with a significantly greater incidence in children ${ }^{20}$.

Functional evaluation was possible in 21 prospective cases FIM and Barthal index improve almost in all cases as these factor were not significantly related to sex, age length of rehabilitation pathogenesis, or completeness or neurologic level of injury. However the functional gain in cases with incomplete spinal cord injury is more than those of complete spinal cord injury. ${ }^{19}$

The deformity evaluation was done in 21 prospective cases and four retrospective cases in which follow up was possible. Kyphotic deformity of more than 15 degree present in $13(52 \%)$ cases in 3 cases cobbs angle not measurable due to high thoracic lesion, there is no deformity in 9 cases. In all 13 cases presenting with deformity at the time of admission progression (4.23 degree) in deformity was noted in follow up. In our study group deformity were present and progress mainly in those patient who sustain injuries in thoracic region $\left(T_{3}-T_{7}\right)$ 
and thoracolumber region $\left(\mathrm{T}_{11}-\mathrm{L}_{2}\right)$. These findings show that the level and extent of spinal injury and age at the time of injury are determinant of the development of deformity.

\section{CONCLUSIONS}

With this study we conclude that the incidence, mechanism of injury, vertebral and neurological level of injury, outcome, development of deformity are different in different age groups which are reflection of anatomical, biomechanical and behavioral difference between these age groups and differ them from spinal injuries in adult in many aspects.

\section{REFERENCES}

[1]. 1-Givens TG, Polly KA, Smith GF, et al. Pediatric cervical spine injury. A three years experience. J. Trauma. 1996; 41:310-314.

[2]. 2- Finch GD, Barnes MJ: Major cervical spine injuries in children and adolescent. J pediatric orthop. 1998;18:811-814.

[3]. 3- Orenstein JB, Klein BL, Gotschall CS, et al. Age and outcome of pediatric cervical spine injury.11 year experience. Pediatric Emerg Care. 1994;10:132-137.

[4]. 4-Hadly MN, Zabramski JM, Browner cm, et al. pediatric spinal trauma: review of 122 cases of spinal cord and vertebral column injuries. J. Neurosurgery. 1988; 68: 18-24.

[5]. 5-Eleraky MA, Theodore N, Adams M, et al. pediatric cervical spinal injuries: report of 102 cases and review of literature. J. Neurosurgery 2000; 92:12-17.

[6]. 6-Evan R. Kokoska, Martin S.Keller, Marcus S. Rallo, Thomas R. Weber. Characteristics of pediatric cervical spine injuries. Journal of pediatric surgery online. 2001; 36:2.

[7]. 7-Ruge JR, Sinson GP, McLone DG, et al. Pediatric spinal injury. The very young. J Neurosurgery. 1988; 68:2530 .

[8]. 8-Hill SA, Miller CA, Kosnik EJ. et al. Pediatric neck spinal injuries. A clinical study. J Neurosurgery. 1984; 60:700-706.

[9]. 9- Fraken EA Jr. spinal cord injury in the newborn infant. Pediatric Radiol. 1975; 3:101-104.

[10]. 10-Bayram Cirak, Suzan Ziegfeld, Vinita Mishra Knight, David Chang, et al. spinal injuries in children. Journal of Pediatric Surgery April 2004; 39(4).

[11]. 11-Reakate HL, Theodore N, Sonntage YKH, et al .Pediatric spinal and spinal cord trauma. State of the art for the third millennium. Child's Nerv System. 1999; 15:743-750.

[12]. 12-Subach BR, McLaughlin MR, Albright AL. et al. current management of pediatric atlantoaxial rotary subluxation. Spine 1998; 23:2174-2179.

[13]. 13- Peter Viccellio, Harold Simon, Barry D Pressman, et al. for the NEXUS Group. A prospective multicenter study of cervical spine injury in children. Pediatrics August 2001; 108(2):20.

[14]. 14-Pang D, Wilberger JE Jr : spinal cord injury without radiographic abnormalities in children. J Neurosurgery 1982; 57:114-129.

[15]. 15-Anderson JM, Shutt AH. Spinal injury in children. A review of 156 cases seen from 1950 through 1978. Mayo Clin. Proc.1980; 55:499-504.

[16]. 16-JateenC.Patel, Joseph J.Tepas, Daniel L. Mollitt, Pam Pieper. Pediatric cervical spine injuries: defining the disease. Journal of pediatric surgery online. 2001;36:2.

[17]. 17- Parisini P, Di Silvestre M, Grehhi T. Treament of spinal fracture in children and adolescent: long term result in 44 patients. Spine 2002; 27 (18).

[18]. 18- Kaps HP, Badke A. Development of the spine after traumatic spinal cord injury in children and adolescents. Orthopead.2005; 34(2):128-30; 132-6.

[19]. 19- Garcia RA, Gaeblar- Spira D, Sisung C. et al. Functional improvement after pediatric spinal cord injury. Am. Physic Med. Rehabil. 2002; 81:458-463.

[20]. 20- Wang, Michael Y, Hoh, Daniel J., Leary, Scott P. et al. High rates of neurological improvement following severe traumatic pediatric spinal cord injury. Spine. 2004; 29 (13): 1493-1497. 